\title{
THE
}

\section{A Physics-Based Parameterization of Air-Sea Momentum Flux at High Wind Speeds and Its Impact on Hurricane Intensity Predictions}

II-Ju Moon

University of Rhode Island

Isaac Ginis

University of Rhode Island, iginis@uri.edu

Tetsu Hara

University of Rhode Island, thara@uri.edu

Biju Thomas

University of Rhode Island

Follow this and additional works at: https://digitalcommons.uri.edu/gsofacpubs

\section{Citation/Publisher Attribution}

Moon, I., Ginis, I., Hara, T., \& Thomas, B. (2007). A Physics-Based Parameterization of Air-Sea Momentum Flux at High Wind Speeds and Its Impact on Hurricane Intensity Predictions. Mon. Wea. Rev., 135, 2869-2878. doi: 10.1175/MWR3432.1 Available at: https://doi.org/10.1175/MWR3432.1

This Article is brought to you for free and open access by the Graduate School of Oceanography at DigitalCommons@URI. It has been accepted for inclusion in Graduate School of Oceanography Faculty Publications by an authorized administrator of DigitalCommons@URI. For more information, please contact digitalcommons-group@uri.edu. 


\title{
A Physics-Based Parameterization of Air-Sea Momentum Flux at High Wind Speeds and Its Impact on Hurricane Intensity Predictions
}

\author{
Il-Ju Moon,* IsaAc Ginis, Tetsu Hara, and Biju Thomas \\ Graduate School of Oceanography, University of Rhode Island, Narragansett, Rhode Island
}

(Manuscript received 12 December 2005, in final form 10 October 2006)

\begin{abstract}
A new bulk parameterization of the air-sea momentum flux at high wind speeds is proposed based on coupled wave-wind model simulations for 10 tropical cyclones that occurred in the Atlantic Ocean during 1998-2003. The new parameterization describes how the roughness length increases linearly with wind speed and the neutral drag coefficient tends to level off at high wind speeds. The proposed parameterization is then tested on real hurricanes using the operational Geophysical Fluid Dynamics Laboratory (GFDL) coupled hurricane-ocean prediction model. The impact of the new parameterization on the hurricane prediction is mainly found in increased maximum surface wind speeds, while it does not appreciably affect the hurricane central pressure prediction. This helps to improve the GFDL model-predicted wind-pressure relationship in strong hurricanes. Attempts are made to provide physical explanations as to why the reduced drag coefficient affects surface wind speeds but not the central pressure in hurricanes.
\end{abstract}

\section{Introduction}

The transfer of momentum between the atmosphere and the ocean is a crucial subject in atmospheric modeling and weather forecasting. In most global and mesoscale atmospheric models the momentum exchange at the sea surface is parameterized using the drag coefficient $\left(C_{d}\right)$ that increases approximately linearly with wind speed. This behavior of the $C_{d}$ is based on extrapolations from field measurements in weak-tomoderate wind regimes less than $25 \mathrm{~m} \mathrm{~s}^{-1}$. In strong wind conditions, it has been reported that the Geophysical Fluid Dynamics Laboratory (GFDL) hurricane prediction model, used operationally by the U.S. National Hurricane Center, tends to underestimate the surface wind speed for a given central pressure (Ginis et al. 2004, see their Fig. 2). This may be partly attributed to an insufficient horizontal grid resolution. However, a more likely reason is the inadequate represen-

\footnotetext{
* Current affiliation: College of Ocean Science, Cheju National University, Aradong, Jejusi, South Korea.
}

Corresponding author address: Il-Ju Moon, Graduate School of Oceanography, University of Rhode Island, Narragansett, RI 02882.

E-mail: mij@gso.uri.edu

DOI: 10.1175/MWR3432.1

(C) 2007 American Meteorological Society tation of the physical processes that affect air-sea momentum exchanges at high wind speeds.

Recently, Moon et al. $(2004 a, b, c)$ used a coupled wave-wind $(\mathrm{CWW})$ model to show that the drag coefficient levels off (or even decreases) at wind speeds exceeding $30 \mathrm{~m} \mathrm{~s}^{-1}$. This behavior of the $C_{d}$ at high wind speeds was also found in recent field observations of Powell et al. (2003), laboratory experiments of Alamaro et al. (2002) and Donelan et al. (2004), and theoretical studies of Emanuel (2003) and Makin (2005). Although physical explanations vary and are not conclusive, there is a general consensus that the $C_{d}$ ceases to increase with wind speed at high wind speeds. Therefore, the present parameterization of the $C_{d}$ in atmospheric models, where the $C_{d}$ linearly increases with wind speed, clearly overestimates the momentum flux at high wind speeds. The overestimated momentum flux likely contributes to the limited skill of numerical hurricane intensity prediction. Reduced $C_{d}$ at high winds will likely have a significant impact not only on hurricane modeling but also on other atmospheric and oceanic modeling focusing on high wind conditions. However, no studies have been performed to investigate the effect of reduced $C_{d}$ at high wind speeds on atmospheric and oceanic modeling.

Since direct flux measurements at very high wind speeds are still extremely limited (Kepert 2004; French 2005), theoretical and numerical approaches may pro- 
vide a useful and complementary way to develop new flux parameterizations in a wide range of wind conditions without the limitations of available observational data. This study proposes a simple parameterization of air-sea momentum fluxes for high wind conditions, based on the CWW model simulations (Moon et al. 2004c) for 10 tropical cyclones in the Atlantic Ocean during 1998-2003. The new parameterization is compared with available observations and results from other theoretical/numerical studies, and is applied to the GFDL coupled hurricane-ocean prediction system to investigate its effect on real hurricane simulations.

In section 2, the main features of the CWW model will be briefly discussed since the present approach strongly depends on the results of the CWW model simulations. A new parameterization based on hurricane simulation results is proposed in section 3. Section 4 describes the numerical experiments for real hurricanes using the new flux parameterization. The summary and conclusion are given in the last section.

\section{CWW model}

In the CWW model the surface wave directional frequency spectrum near the spectral peak is calculated using the WAVEWATCH-III (Tolman 2002) model and the high-frequency part of the spectrum is parameterized using the theoretical model of Hara and Belcher (2002). The complete wave spectrum is then introduced to the wave boundary layer model of Hara and Belcher (2004) to estimate the drag coefficient at different wind and wave conditions. The CWW model treats the wind stress as a vector quantity to consider the influence of dominant waves that propagate at a large angle to the local wind. Therefore, the method allows us to estimate the wind stress vectors for any given surface wave field, even for the complex seas encountered under tropical cyclones. The details of the model are provided in Moon et al. (2004a,b).

The CWW model has been applied for constant winds from 10 to $45 \mathrm{~m} \mathrm{~s}^{-1}$ (Moon et al. 2004a), idealized hurricanes with various forward speeds (Moon et al. 2004b), and 10 real hurricanes in the Atlantic Ocean during 1998-2003 (Moon et al. 2004c). The main results of these studies are that the neutral drag coefficient levels off at high wind speeds and the nondimensional roughness length is mainly determined by two parameters: the input wave age (wave age determined by the peak frequency of wind energy input) and the wind speed, regardless of the complexity of the wave field. The model-simulated drag coefficients are generally consistent with the recent results of field observations, laboratory experiments, and theoretical studies at high wind speeds (Powell et al. 2003; Alamaro et al. 2002; Donelan et al. 2004; Emanuel 2003).

\section{New parameterization of air-sea momentum flux}

At low winds (wind speed less than $12.5 \mathrm{~m} \mathrm{~s}^{-1}$ ) the bulk parameterization used in the operational GFDL hurricane model is consistent with previous observations. Therefore, the roughness length $\left(z_{0}\right)$ in our parameterization is identical to the bulk parameterization and is calculated using a constant Charnock coefficient or nondimensional roughness length $\left(z_{\mathrm{ch}}\right)$, defined as

$$
z_{\mathrm{ch}}=\frac{z_{0} g}{u_{*}^{2}}=0.0185
$$

where $u_{*}$ is the friction velocity and $g$ is the gravitational acceleration. In neutral conditions the neutral wind speed $(W)$ at 10-m height is described by the logarithmic profile,

$$
W=\frac{u_{*}}{\kappa} \ln \frac{10}{z_{0}},
$$

where $\kappa$ is the von Kármán constant $(=0.4)$ and the unit of $z_{0}$ is meters. From Eqs. (1) and (2), the friction velocity $u_{*}\left(\mathrm{~m} \mathrm{~s}^{-1}\right)$ can be expressed as a function of $W$ $\left(\mathrm{m} \mathrm{s}^{-1}\right)$ using polynomial fitting,

$$
u_{*}=0.001 W^{2}+0.028 W, \quad W \leq 12.5 \mathrm{~m} \mathrm{~s}^{-1},
$$

where the regression coefficient is 0.99 . The roughness length can be also expressed as a function of $W$ :

$$
z_{0}=\frac{0.0185}{g}\left(0.001 W^{2}+0.028 W\right)^{2}, \quad W \leq 12.5 \mathrm{~m} \mathrm{~s}^{-1} \text {. }
$$

Our parameterization of $z_{0}$ at higher winds speeds $\left(W>12.5 \mathrm{~m} \mathrm{~s}^{-1}\right)$ is based on the CWW simulations of 10 tropical cyclones that occurred in the Atlantic Ocean during 1998-2003, reported by Moon et al. (2004c). Their scatterplot of calculated $z_{0}$ against wind speed is reproduced in Fig. 1a (plus signs). We then establish an empirical relationship between $z_{0}$ and $W$ by fitting the CWW results with a linear regression function:

$$
z_{0}=(0.085 W-0.58) \times 10^{-3}, \quad W>12.5 \mathrm{~m} \mathrm{~s}^{-1},
$$

where the regression coefficient is 0.87 (see Fig. 1a, blue line). 

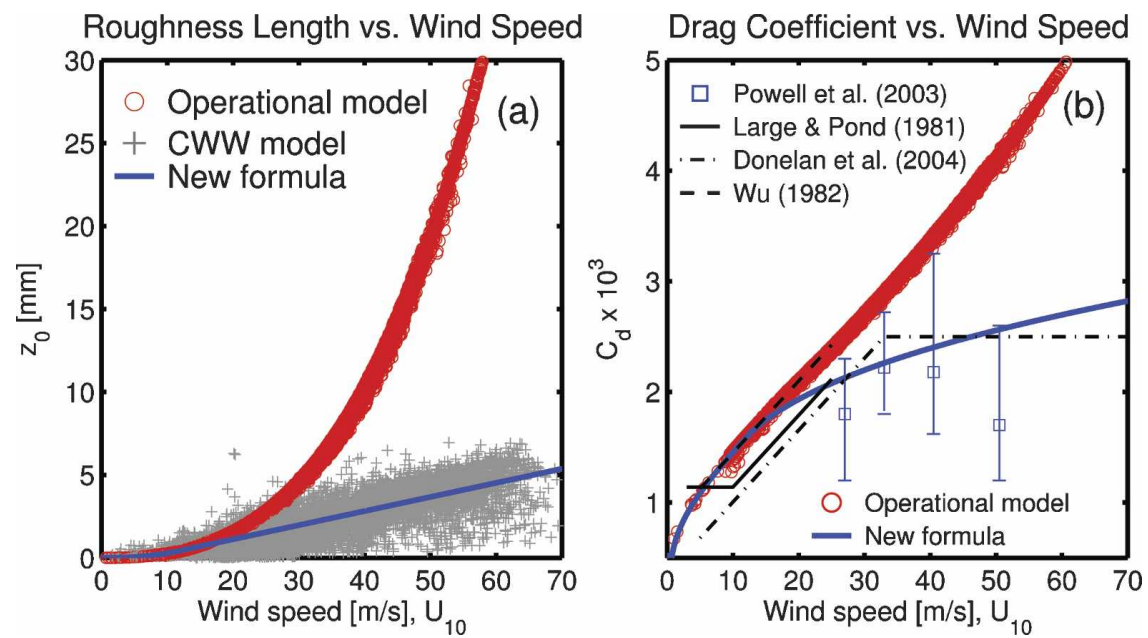

FIG. 1. (a) Roughness length and (b) drag coefficient vs wind speed in $\mathrm{m} \mathrm{s}^{-1}$ at $10 \mathrm{~m}$. Red circles and gray plus signs are the results of the Hurricane Ivan forecast (initial time: 0000 UTC 12 Sep 2004) from the operational GFDL hurricane model and the CWW model, respectively; blue lines in (a) and (b) are the new $z_{0}$ and $C_{d}$ formulations based on the neutral 10-m wind speed, respectively; the black solid line is data according to Large and Pond (1981); the dashed-dotted line is data according to Donelan et al. (2004); squares are averaged values from the data of Powell et al. (2003); vertical bars are the range of estimates based on $95 \%$ confidence.

The expressions (4) and (5) match well at $W=12.5$ $\mathrm{m} \mathrm{s}^{-1}$ with the difference of $1 \times 10^{-6}$ and together make up our new parameterization of $z_{0}$ for all wind speeds. In most ocean models the air-sea momentum flux is calculated using the neutral drag coefficient $C_{d}$ (Flather 1994; Tang et al. 1996). An expression of the neutral $C_{d}$ as a function of $W$ can be obtained by introducing (4) or (5) into

$$
C_{d}=\kappa^{2}\left(\ln \frac{10}{z_{0}}\right)^{-2}
$$

In many atmospheric and weather prediction models, the air-sea momentum flux is calculated using $z_{0}$ as a function of $u_{*}$ (Charnock 1955; Kurihara and Tuleya 1974). Such a formulation is obtained by first expressing $W$ as a function of $u_{*}$ from (2) and (5),

$$
W=-0.56 u_{*}^{2}+20.255 u_{*}+2.458,
$$

using polynomial fitting (where the regression coefficient is 0.99), and then combining (1), (5), and (7):

$$
\begin{aligned}
z_{0}= & \frac{0.0185}{g} u_{*}^{2}, \quad W \leq 12.5 \mathrm{~m} \mathrm{~s}^{-1} \text { and } \\
z_{0}= & {\left[0.085\left(-0.56 u_{*}^{2}+20.255 u_{*}+2.458\right)\right.} \\
& -0.58] \times 10^{-3}, \quad W>12.5 \mathrm{~m} \mathrm{~s}^{-1} .
\end{aligned}
$$

Figure $1 \mathrm{~b}$ compares the neutral drag coefficient estimated from our new formulation (thick blue line) with the bulk parameterization used in the operational GFDL model, the results from Wu (1982), Large and Pond (1981), Donelan et al. (2004), and Powell et al. (2003). For $W \leq 12.5 \mathrm{~m} \mathrm{~s}^{-1}$, the new $C_{d}$ represents a monotonic increase with wind speed as in the operational GFDL model and is similar to that of Wu (1982). But it is slightly higher than those of Large and Pond (1981) and Donelan et al. (2004). For $W>12.5 \mathrm{~m} \mathrm{~s}^{-1}$, the new $C_{d}$ tends to level off between 2 and 3 . This is similar to the trend observed by Donelan et al. (2004) and is within the error bars estimated by Powell et al. (2003), although it is somewhat higher than their averaged values (squares in Fig. 1b). At $60 \mathrm{~m} \mathrm{~s}^{-1}$ wind speed, the new $C_{d}$ is half of the value used in the operational GFDL model.

It should be noted that at high wind speeds the boundary layer close to the surface is nearly neutral since $\ln z / z_{0} \gg f_{m}(z / L)$, where $f_{m}$ is the universal function and $L$ is the Monin-Obukhov (MO) length. At low winds, however, the stability effect may be important. In the following numerical experiments the parameterization in (8) is used to define the roughness length, and then the real $10-\mathrm{m}$ wind speed and exchange coefficients are calculated through the iteration using stability parameters and universal functions based on the MO similarity theory (Liu et al. 1979; DeCosmo et al. 1996). 


\section{Impact of the new momentum flux parameterization on the GFDL model hurricane predictions}

The proposed parameterization has been tested for real hurricane predictions using the operational GFDL hurricane prediction model, which is coupled with the Princeton ocean model. The GFDL model is a primitive equation model formulated in latitude, longitude, and sigma coordinates with 42 levels in the vertical. Major features of the model are given by Kurihara et al. (1998). The model includes a multiply nested movable mesh configuration and model initialization by the method of vortex replacement (Kurihara et al. 1993). The 2005 version of the GFDL model, which has a movable innermost mesh of $1 / 12^{\circ}$, is used in the present experiments. Five-day forecasts are conducted for 11 cases of Hurricanes Isabel (2003), Ivan (2004), Frances (2004), Jeanne (2004), and Charley (2004), that is, four cases for Isabel (0000 UTC 10 September, 1800 UTC 18 September, 0000 UTC 12 September, and 0000 UTC 12 September), four cases for Ivan (0000 UTC 10 September, 0600 UTC 10 September, 0000 UTC 11 September, and 0000 UTC 12 September), and one case each for Frances (0600 UTC 1 September), Jeanne (0000 UTC 19 September), and Charley (1800 UTC 11 August). The initial forecast times of each hurricane are carefully selected to consider various situations. During the forecast periods, Hurricanes Isabel and Ivan reached up to category 5 on the Saffir-Simpson scale. Charley (category 4) made landfall and underwent both developing and decaying stages. Frances was in a weakening stage from category 4 to 1 , while Jeanne was in a developing stage from category 1 to 2 .

Two forecast runs are conducted for each case. In both experiments, the flux calculations are made using the GFDL model original bulk parameterization based on the MO similarity theory. The neutral drag coefficient is expressed by Eq. (6). The neutral exchange coefficient of heat and water (assumed equal, $C_{k}$ ) is expressed as (DeCosmo et al. 1996; Zeng et al. 1998; Kurihara and Tuleya 1974)

$$
C_{k}=k^{2}\left(\ln \frac{10}{z_{0}}\right)^{-1}\left(\ln \frac{10}{z_{T}}\right)^{-1},
$$

where $z_{T}(\mathrm{~m})$ is the roughness length for heat and humidity fluxes (assumed equal).

In the first control run (operational GFDL model), both $z_{0}$ and $z_{T}$ are defined by Charnock's relation, $0.0185 \mathrm{~g} / u_{*}^{2}$, of the formulation in (1). In the second run, $z_{T}$ is defined by the same Charnock's relation, but $z_{0}$ is defined by new empirical formulation in (8). This implies that $C_{k}$ in the second run is also decreased due to

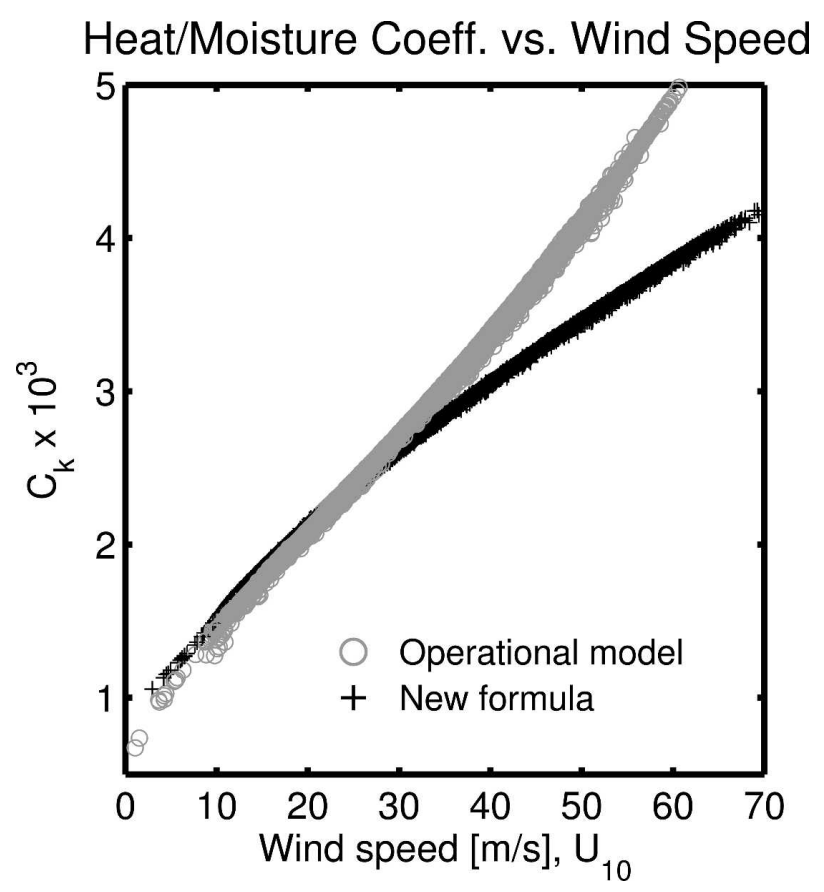

FIG. 2. Scatterplot of the neutral heat/humidity coefficient against wind speed at $10 \mathrm{~m}$ from the Hurricane Ivan forecast (initial time: 0000 UTC 12 Sep 2004). Circles are from the operational GFDL hurricane model and plus signs are from the GFDL model run using the new momentum flux parameterization.

the reduced values of $z_{0}$ by the new formula at high wind speeds (see Fig. 2), although the heat and humidity parameterizations are not modified here. It is certainly possible that the value of $z_{T}$ at high wind speeds is also different from the Charnock's relation. However, the objective of this study is to focus on the effect of decreased $z_{0}$, and therefore $z_{T}$ is kept unchanged.

The ratio of the neutral drag and heat/humidity coefficients, $C_{k} / C_{d}$, is a key parameter in tropical cyclone intensity (Emanuel 1995). Figure 3 shows the scatterplot of $C_{k} / C_{d}$ for two runs. In the first run, $C_{k} / C_{d}$ is 1 , while in the second run it lies in the range 0.7-1.4 and increases as wind speed increases. The latter trend is qualitatively consistent with Emanuel (1995) who shows, using a hurricane model, that the ratio lies in the range $0.75-1.5$ and increases with maximum wind when hurricanes intensify. This, however, contradicts the studies by Liu et al. (1979) and Geernaert et al. (1987), who show that the ratio $C_{k} / C_{d}$ is less than 1 and decreases with increasing wind. As Bao et al. (2002) point out, the behavior of $C_{k} / C_{d}$ at high winds is still controversial due to lack of reliable observation data under high wind conditions.

The effect of the new flux parameterization on hurricane predictions is investigated in terms of the forecast skill for the surface maximum wind speed (MWS), 
Ratio of $\mathrm{C}_{\mathrm{k}}$ and $\mathrm{C}_{\mathrm{d}}$ vs. wind speed

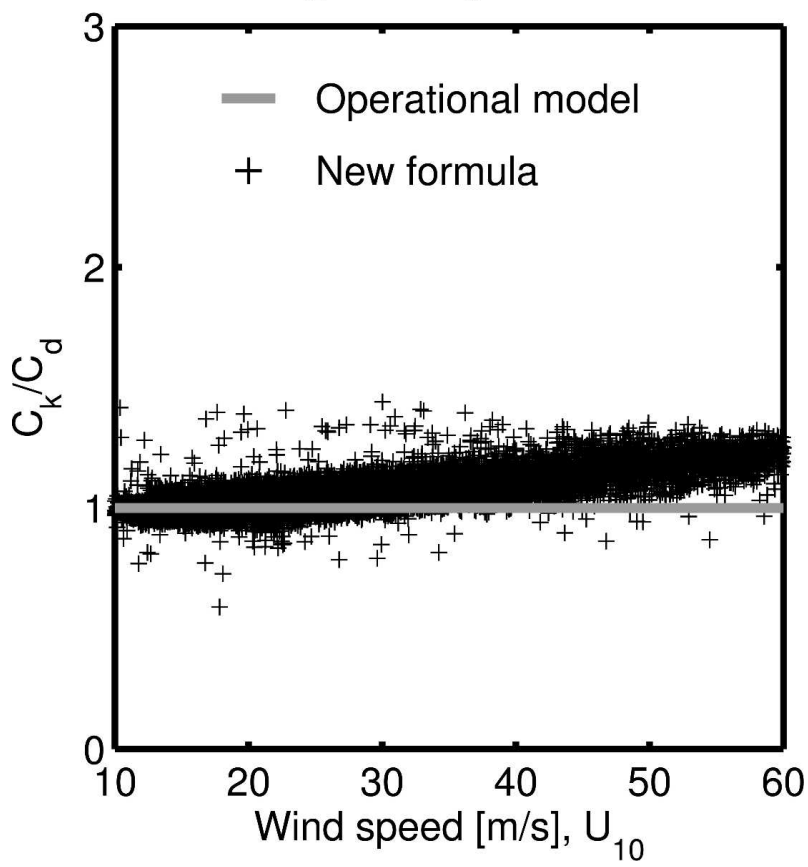

FIG. 3. Scatterplot of the ratio $\left(C_{k} / C_{d}\right)$ of neutral drag coefficient and heat/humidity coefficients against wind speed at $10 \mathrm{~m}$ from the Hurricane Ivan forecast (initial time: 0000 UTC 12 Sep 2004). A gray solid line is from the operational GFDL hurricane model and plus signs are from the GFDL model run using the new momentum flux parameterization.

central pressure, and track of a hurricane. Figure 4 shows an example of 5-day forecast run for Hurricane Ivan (initial forecast time: 0000 UTC 12 September 2004) using the two flux parameterizations. Here, Hurricane Ivan reached category 5 and sustained its strength for a few days before weakening. The major differences between the two experiments are found in the MWS forecast. The run using the new formula predicts overall higher wind speeds (about 10\% increase) than the operational model with the largest difference of about $10 \mathrm{~m} \mathrm{~s}^{-1}$. The results with the new formula are more consistent with the observations, therefore indicating the improved forecast skill. However, such distinct difference between the two experiments is not found in the central pressure prediction (Fig. 4b). The track forecast is changed only slightly by using the new formula. To investigate how the new formula affects the structure of the hurricane, the surface wind fields at 1800 UTC 12 September from the two models are compared in Fig. 5 with the real-time surface wind analysis of the National Oceanic and Atmospheric Administration's (NOAA's) Hurricane Research Division (HRD; Powell et al. 1998) at 1930 UTC 12 September. The

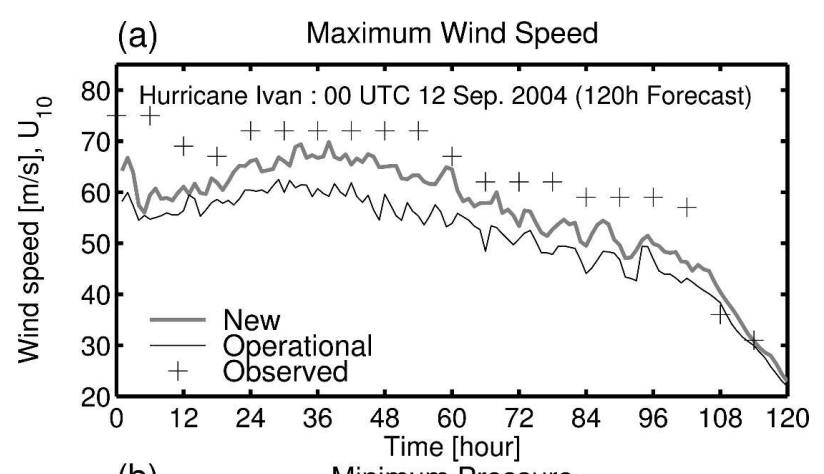

(b) Minimum Pressure

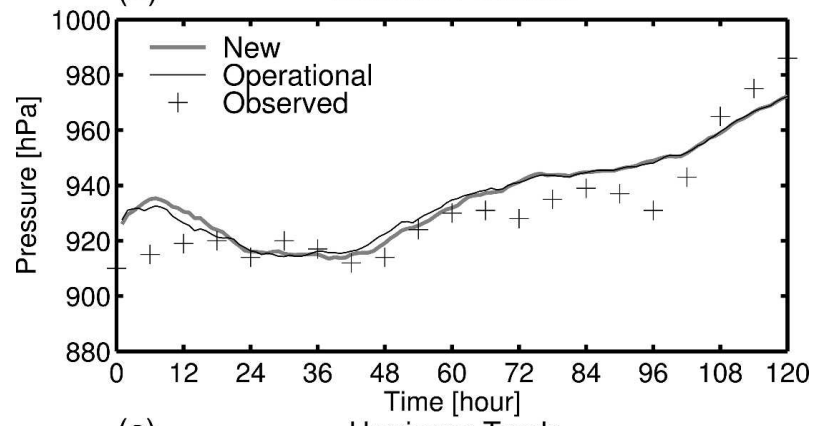

(c) Hurricane Track

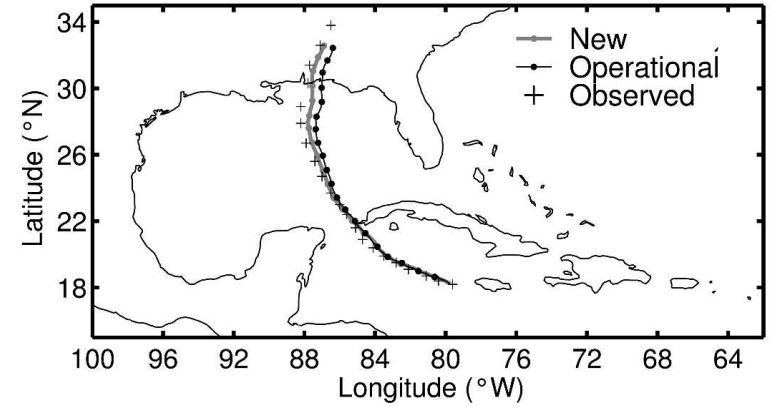

FIG. 4. Forecasts of the (a) MWS, (b) central pressure, and (c) track for Hurricane Ivan (initial time: 0000 UTC 12 Sep 2004). The thin lines are the operational GFDL hurricane model forecast, thick gray lines are the GFDL model forecast using the new momentum flux parameterization, and plus signs are observations.

figure shows that the asymmetric wind structure appearing in the HRD wind is well reproduced in both model simulations, but that the wind structure near the eyewall, particularly the position and shape of the strong wind area, is better simulated by the new formula.

Another example of the improvements in the MWS forecasts with the new flux parameterization is presented in Fig. 6 for Hurricane Frances (initial forecast time: 0000 UTC 1 September 2004). In this case, Hurricane Frances was in a weakening stage from category 4 to 1 and making landfall at Florida. The overall results for Frances are very similar to the case of Hurricane Ivan, that is, the maximum wind speed increases but the 
(a) Wind Field: Ivan, Initial time: $00 Z 12$ Sep

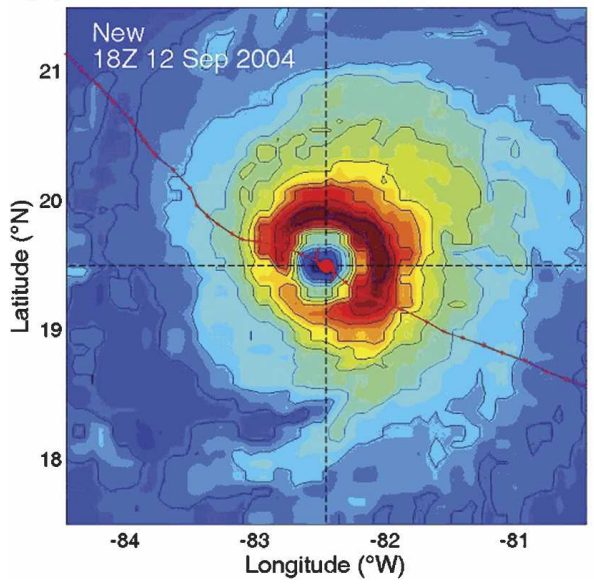

(c) HRD Wind Field (19:30Z 12 Sep. 2004)

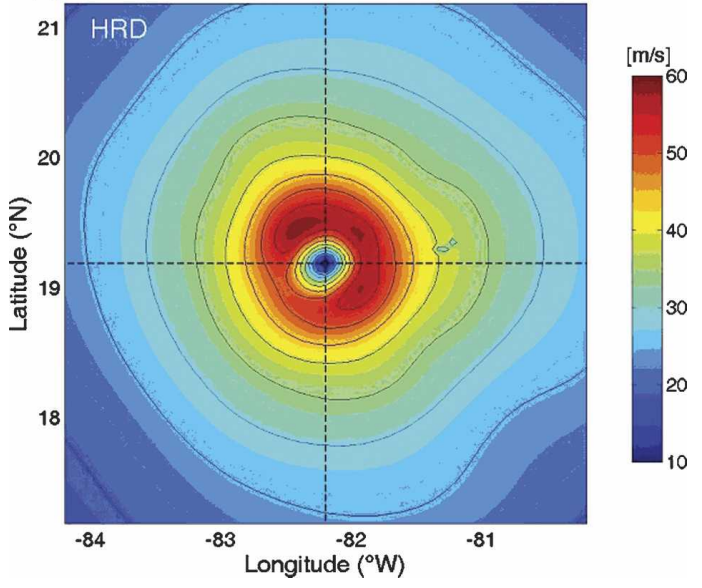

(b) Wind Field: Ivan, Initial time: $00 Z 12$ Sep

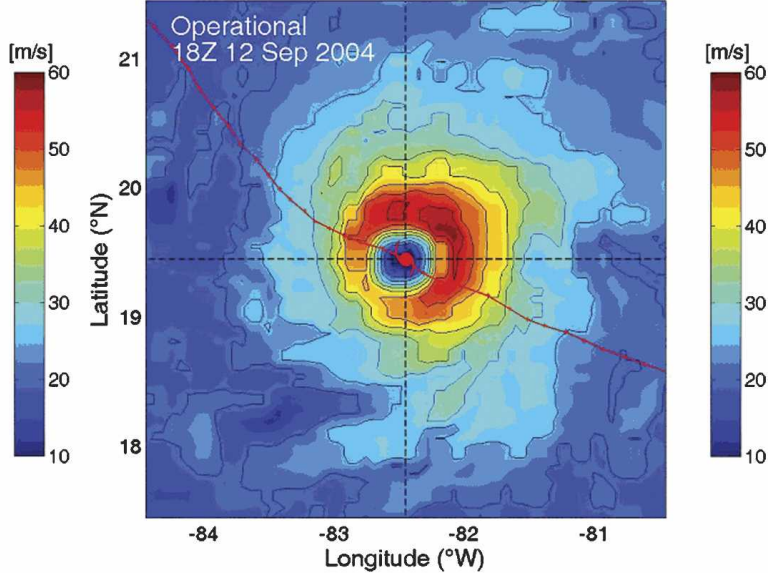

FIG. 5. Spatial distributions of surface wind in Hurricane Ivan at 1800 UTC 12 Sep 2004 in (a) the GFDL hurricane model with the new flux parameterization, (b) the operational GFDL model initialized at 0000 UTC 12 Sep 2004, and (c) the HRD wind analysis at 1930 UTC 12 Sep 2004. central pressure changes little with the new flux formula. While it is expected that the maximum wind is increased by reducing the surface drag, it is less clear why the central pressure is not appreciably changed. The pressurewind relationship is one of the most difficult parameters to predict and it is likely sensitive to the model surface layer physics and the convection parameterization.

Figure 7 compares the SST as well as the surface momentum flux (MF), heat/humidity flux (HF), and energy dissipation rate, averaged within $100-\mathrm{km}$ radius of the hurricane center for the Ivan case shown in Fig. 4 , in the two models. Figure 7 a shows that the maximum SST drop reached $2.5^{\circ} \mathrm{C}$ when Ivan entered the Gulf of Mexico and again before landfall. This is consistent with Walker et al. (2005) who observed a significant surface cooling $\left(3^{\circ}-7^{\circ} \mathrm{C}\right)$ in two large areas along Ivan's track in the Gulf of Mexico. Considering that the SST drop in Fig. 7a is averaged over a 100-km radius around the hurricane center, it appears that the model-simulated SST cooling is reasonable. It is seen that the MF is significantly reduced by the new formula
(Fig. 7b) and this seems to cause an increase of the MWS. On the other hand, the averaged HF (Fig. 7c; i.e., energy input) is not changed much because it is balanced by both the positive effects (from less cooling due to the reduced $\mathrm{MF}$ and from increased wind speeds) and the negative effect (from the decrease of the heat transfer coefficient). This implies that the SST cooling plays a significant role in this balance, which is an interesting and important feature of the fully coupled atmosphere-ocean system.

For a mature hurricane the amount of total kinetic energy generated is equal to that being dissipated by friction. The dissipation rate per unit area is the MF times the wind speed (Emanuel 1999). A comparison of downward kinetic energy fluxes (energy dissipation) between the two models (Fig. 7d) shows that the change of energy due to the new parameterization is relatively small (the reduction of the MF is compensated by the increase of the wind speed), particularly after $44 \mathrm{~h}$. This may explain the similar central pressures between the two models in Figs. $4 \mathrm{~b}$ and $6 \mathrm{~b}$. 
(a)

Maximum Wind Speed

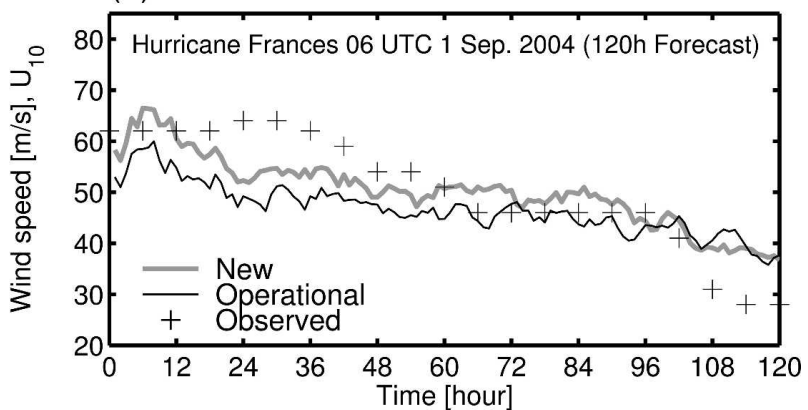

(b)

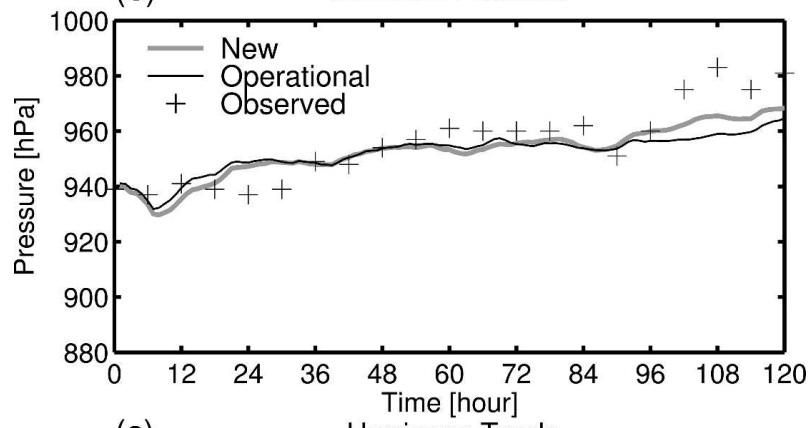

(c)

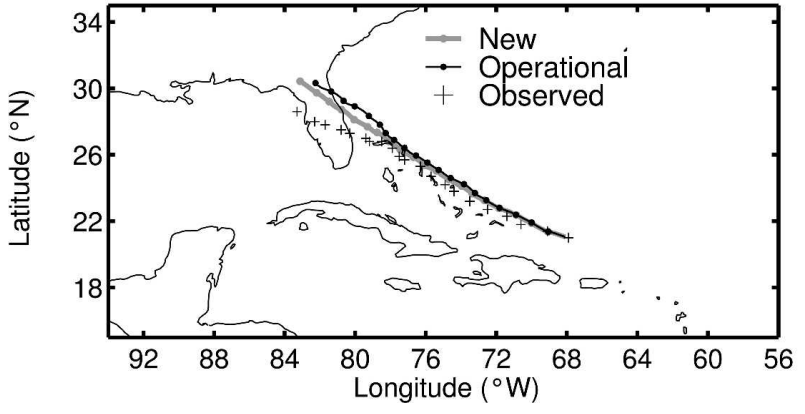

FIG. 6. Same as in Fig. 4 but for Hurricane Frances (initial time: 0600 UTC 1 Sep 2004).

For all 11 cases, predictions of the central pressure and the MWS between 2 models are compared in Fig. 8. The figure shows that the new flux parameterization tends to increase the MWS but does not affect the central pressure under a wide range of conditions. Figure 9 compares the MWS from 2 models with observations during 11 forecasts of 5 hurricanes. This shows that the predicted MWS with the new formula are more consistent with observations than the one from the operational model. In Fig. 10, a pressure-wind relationship derived from observations is compared with the predictions from 2 models for the same 11 cases. It is clearly seen that the underestimation of the MWS in the operational GFDL model is significantly improved by using the new flux parameterization, in particular, for strong hurricanes.
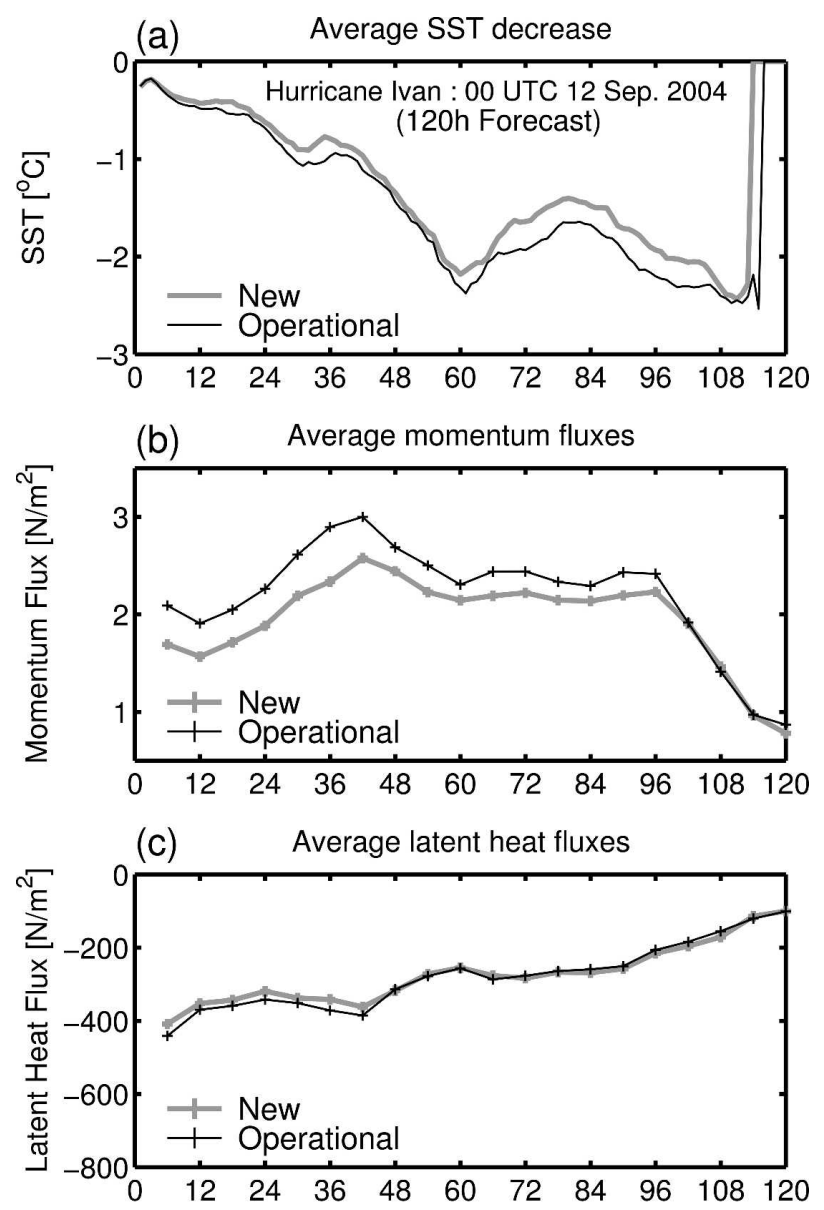

(d) Average downward kinetic energy fluxes

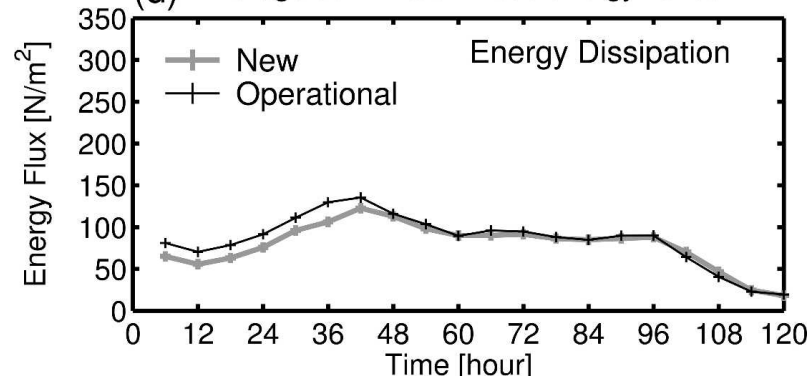

FIG. 7. Time series of the (a) SST decrease, (b) momentum fluxes, (c) latent heat fluxes, and (d) downward kinetic energy fluxes, averaged around the hurricane center (radius $<100 \mathrm{~km}$ ) for the forecast of Hurricane Ivan (initial time: 0000 UTC 12 Sep 2004). Thin lines are from the operational GFDL hurricane model and thick gray lines are from the GFDL model run using the new momentum flux parameterization.

Therefore, it is expected that the new flux parameterization contributes to the overall improvement of the hurricane MWS forecast in the GFDL model, although more real case forecasts are necessary to confirm these results. 

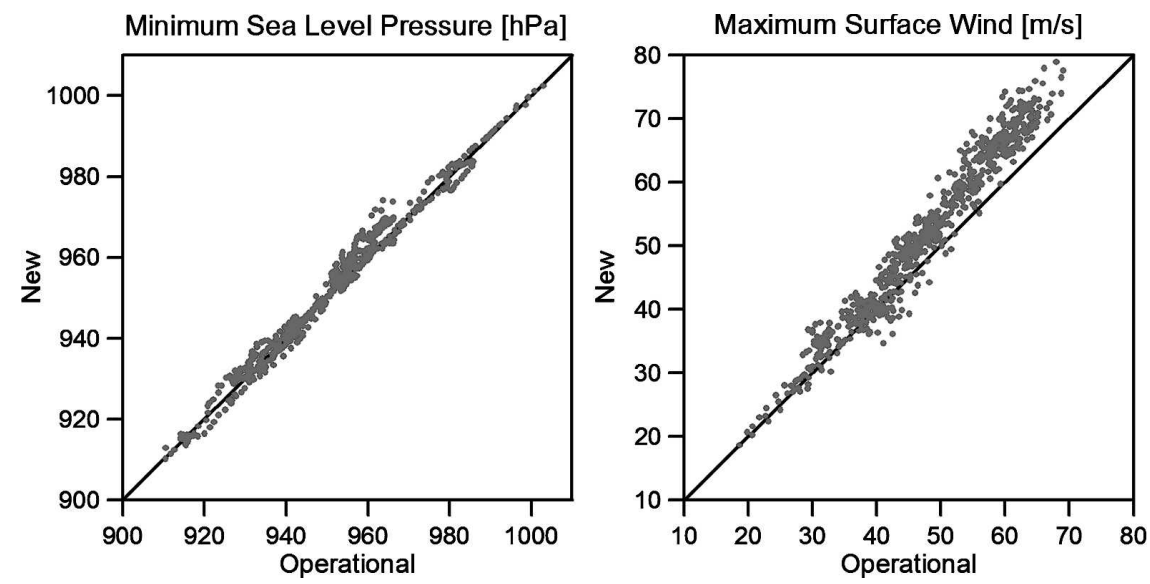

FIG. 8. Comparisons between the operational GFDL hurricane model and the GFDL model with the new flux parameterization for (left) simulated central pressure and (right) maximum surface wind during 11 forecasts of Hurricanes Isabel (2003), Ivan (2004), Frances (2004), Charley (2004), and Jeanne (2004).

\section{Summary and conclusions}

In most atmospheric and oceanic models, the air-sea momentum flux at high wind speeds has been parameterized using a bulk formula based on extrapolation from field measurements in weak-to-moderate wind regimes less than $25 \mathrm{~m} \mathrm{~s}^{-1}$. The bulk formula yields

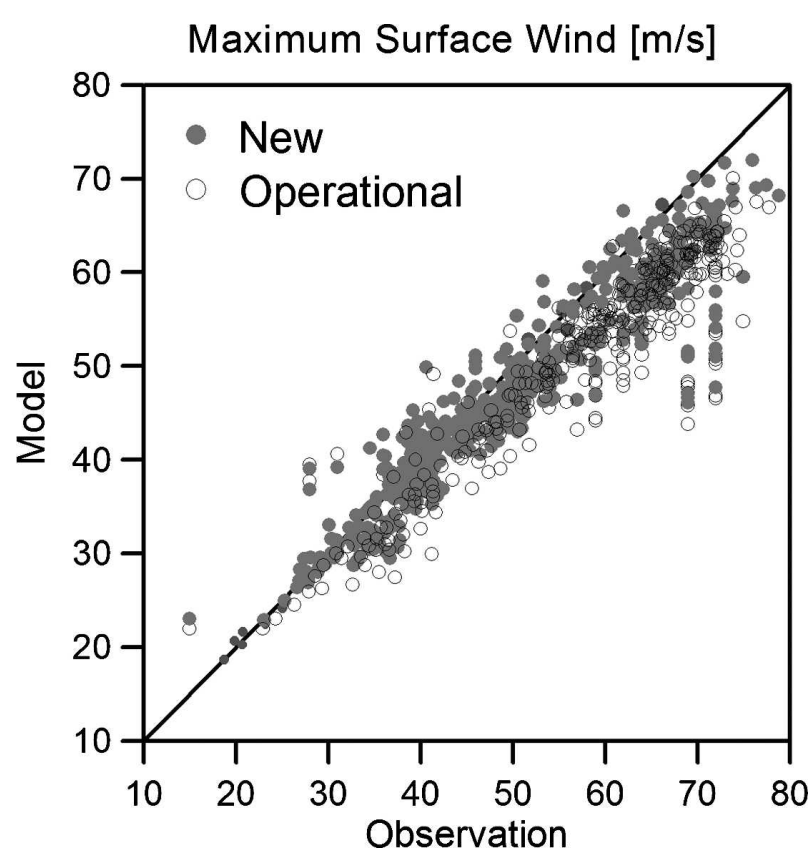

FIG. 9. Comparisons of the maximum surface wind between models and observations during 11 forecasts of Hurricanes Isabel (2003), Ivan (2004), Frances (2004), Charley (2004), and Jeanne (2004). Open circles are from the operational model and filled circles are from the new formula. monotonic increase of the drag coefficient $\left(C_{d}\right)$ with wind speed. However, recent observational, laboratory, theoretical, and modeling studies for high wind speeds (Powell et al. 2003; Donelan et al. 2004; Emanuel 2003; Moon et al. 2004a,b,c) suggest that $C_{d}$ levels off (or even decreases) in high wind conditions.

This study proposes a new and rather simple air-sea momentum flux parameterization, which is consistent with the recent results at high wind speeds. The new parameterization is derived from the CWW model simulations of 10 tropical cyclones in the Atlantic Ocean during 1998-2003 (Moon et al. 2004c). The

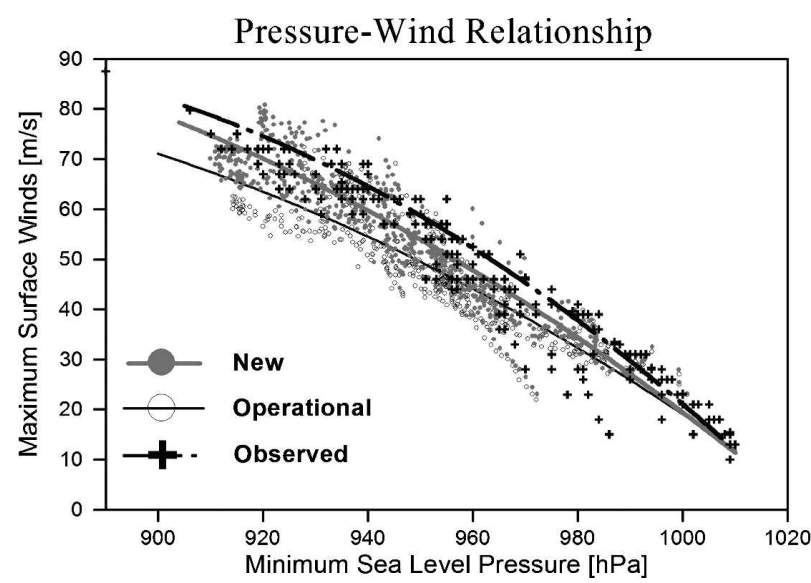

FIG. 10. Comparison of pressure-wind relationships derived from observations (plus signs), the operational GFDL hurricane model (open circles), and the GFDL model with the new flux parameterization (filled circles) from the 11 forecasts of Hurricanes Isabel (2003), Ivan (2004), Frances (2004), Charley (2004), and Jeanne (2004). The lines represent the best polynomial fits (second degree) for each dataset. 
roughness length $\left(z_{0}\right)$ in the new formulation linearly increases with wind speed at high wind speeds. As a result, the new $C_{d}$ tends to level off between the value of 2 and 3, which is similar to the results of Donelan et al. (2004) and within the error bars estimated by Powell et al. (2003).

The new momentum flux parameterization has been tested in 11 forecasts of 5 real hurricanes in the Atlantic Ocean using the operational GFDL hurricane model. While in these experiments the heat and humidity flux calculations are made using the GFDL model original bulk parameterization, the heat/humidity coefficients $\left(C_{k}\right)$ are decreased due to the reduced values of $z_{0}$ by the new formula at high wind speeds. The results show that the new parameterization mainly contributes to an increase of the maximum wind speed (MWS) predictions due to the reduction of the momentum fluxes, but does not appreciably affect the central pressure predictions in these simulations. The analysis of momentum/ heat fluxes and energy dissipation as well as sea surface temperature cooling near the hurricane center reveals that the heat flux remains virtually unchanged by the new momentum parameterization because it is balanced by both the positive effects (from less sea surface cooling due to the reduced momentum flux and from increased wind speeds) and the negative effect (from the decrease of the heat transfer coefficient). It is an important feature of the fully coupled atmosphereocean system that the hurricane-induced SST change plays a significant role in this balance.

The numerical experiments for five hurricanes show that the new parameterization contributes to overall improvement of hurricane MWS predictions as well as pressure-wind relationships prediction, especially for strong hurricanes. In this study, however, the experiments were conducted only for the GFDL hurricane model which suffers from the underestimation of the MWS for the given central pressure. The underestimation of the MWS in high winds may not be true for other numerical prediction models. More simulations with various models will be necessary to substantiate the results reported here.

It is believed that the air-sea momentum flux is not a function of wind speed alone, but depends on the sea state (Toba et al. 1990; Smith et al. 1992). Under hurricanes the sea state varies significantly according to the relative position from the storm center even under the same wind speed (Moon et al. 2003, 2004b). Therefore, the consideration of sea state can lead to an asymmetric distribution for exchange coefficients and fluxes, which may play a significant role in determining the wind structure inside the hurricane core region and may affect hurricane forecasts. However, the consideration of sea state can be accomplished by a full coupling between a hurricane model and a surface wave model that requires very intensive computations. Also, it is yet unclear to what extent hurricane intensity forecasts are sensitive to the sea-state dependence of the exchange coefficients. The proposed formula here neglects the sea-state dependence of the $C_{d}$. Nevertheless, this study provides a useful guidance to oceanic and atmospheric modelers who are interested in the effect of reduced drag coefficient at high wind regimes. The effect of sea-state dependence will be a topic of our future investigations.

In this study we have focused on the impact of the modified momentum flux parameterization on hurricane predictions. The heat flux parameterization has not been modified (except that the roughness length $z_{0}$ has been replaced by a new formula). This is mainly because our understanding of heat flux in high wind conditions is severely limited. Unlike recent major progress in observational studies of the momentum flux, there are still no reliable observations of the heat flux at high wind speeds. It is certainly questionable whether the heat flux parameterization in the operational GFDL model remains valid in high wind conditions. Bao et al. (2002) have shown that great disparity exists in the response of model-simulated hurricanes to different parameterizations. Further studies of the heat flux in high wind conditions (particularly observational studies) are needed to address these questions.

Acknowledgments. This work was supported by the U.S. National Science Foundation through Grants ATM 0406895. This work was also supported by the Korea Meteorological Administration Research and Development Program under CATER 2006-2301 for I.-J. Moon. Authors T. Hara and I. Ginis thank the U.S. Office of Naval Research (CBLAST program, Grant N00014-06-10729) for additional support.

\section{REFERENCES}

Alamaro, M., K. Emanuel, J. Colton, W. McGillis, and J. B. Edson, 2002: Experimental investigation of air-sea transfer of momentum and enthalpy at high wind speed. Preprints, 25th Conf. on Hurricanes and Tropical Meteorology, San Diego, CA, Amer. Meteor. Soc., 667-668.

Bao, J.-W., S. A. Michelson, and J. M. Wilczak, 2002: Sensitivity of numerical simulations to parameterizations of roughness for surface heat fluxes at high winds over sea. Mon. Wea. Rev., 130, 1926-1932.

Charnock, H., 1955: Wind stress on a water surface. Quart. J. Roy. Meteor. Soc., 81, 639-640.

DeCosmo, J., K. B. Katsaros, S. D. Smith, R. J. Anderson, W. A. Oost, K. Bumke, and H. Chadwick, 1996: Air-sea exchange of water vapor and sensible heat: The humidity exchange over 
the sea (HEXOS) results. J. Geophys. Res., 101, 12 00112016.

Donelan, M. A., B. K. Haus, N. Reul, W. J. Plant, M. Stiassnie, H. C. Graber, O. B. Brown, and E. S. Saltzman, 2004: On the limiting aerodynamic roughness of the ocean in very strong winds. Geophys. Res. Lett., 31, L18306, doi:10.1029/2004GL019460.

Emanuel, K. A., 1995: Sensitivity of tropical cyclones to surface exchange coefficients and a revised steady-state model incorporating eye dynamics. J. Atmos. Sci., 52, 3969-3976.

_ 1999: Thermodynamic control of hurricane intensity. $\mathrm{Na}$ ture, 401, 665-669.

— 2003: A similarity hypothesis for air-sea exchange at extreme wind speeds. J. Atmos. Sci., 60, 1420-1428.

Flather, R. A., 1994: A storm surge prediction model for the northern Bay of Bengal with application to the cyclone disaster in April 1991. J. Phys. Oceanogr., 24, 172-190.

French, J., 2005: Flux profile estimates of surface drag in Hurricanes Isabel and Fabian from BAT and Rosemount sensors. CBLAST-Hurricane Science Meeting, Miami, FL, RSMAS/ University of Miami. [Available online at http://www.aoml. noaa.gov/hrd/cblast/cblast4.html.]

Geernaert, G. L., S. E. Larsen, and F. Hansen, 1987: Measurements of the wind stress, heat flux and turbulence intensity during storm conditions over the North Sea. J. Geophys. Res., 92, $13127-13139$.

Ginis, I., A. P. Khain, and E. Morozovsky, 2004: Effects of large eddies on the structure of the marine boundary layer under strong wind conditions. J. Atmos. Sci., 61, 3049-3063.

Hara, T., and S. E. Belcher, 2002: Wind forcing in the equilibrium range of wind-wave spectra. J. Fluid Mech., 470, 223-245.

$\longrightarrow$, and —, 2004: Wind profile and drag coefficient over mature ocean surface wave spectra. J. Phys. Oceanogr., 34, $2345-2358$

Kepert, J. D., 2004: Models and observations of tropical cyclone boundary-layer winds. Extended Abstracts, The Past, Present and Future of Numerical Modeling: 16th Annual BMRC Modeling Workshop, BMRC Research Rep. 104, Melbourne, Australia, BMRC, 77-82.

Kurihara, Y., and R. E. Tuleya, 1974: Structure of a tropical cyclone developed in a three-dimensional numerical simulation model. J. Atmos. Sci., 31, 893-919.

_ - M. A. Bender, and R. J. Ross, 1993: An initialization scheme of hurricane models by vortex specification. Mon. Wea. Rev., 121, 2030-2045.

— , R. E. Tuleya, and M. A. Bender, 1998: The GFDL hurricane prediction system and its performance in the 1995 hurricane season. Mon. Wea. Rev., 126, 1306-1322.

Large, W. G., and S. Pond, 1981: Open ocean momentum flux measurements in moderate to strong wind. J. Phys. Oceanogr., 11, 324-336.
Liu, W. T., K. B. Katsaros, and J. A. Businger, 1979: Bulk parameterization of air-sea exchange of heat and water vapor including the molecular constraints at the interface. J. Atmos. Sci., 36, 1722-1735.

Makin, V. K., 2005: A note on the drag of the sea surface at hurricane winds. Bound.-Layer Meteor., 115, 169-176.

Moon, I.-J., I. Ginis, T. Hara, H. Tolman, C. W. Wright, and E. J. Walsh, 2003: Numerical simulation of sea surface directional wave spectra under hurricane wind forcing. J. Phys. Oceanogr., 33, 1680-1706.

- T. Hara, I. Ginis, S. E. Belcher, and H. Tolman, 2004a: Effect of surface waves on air-sea momentum exchange. Part I: Effect of mature and growing seas. J. Atmos. Sci., 61, 23212333.

— I. Ginis, and T. Hara, 2004b: Effect of surface waves on air-sea momentum exchange. Part II: Behavior of drag coefficient under tropical cyclones. J. Atmos. Sci., 61, 2334-2348.

,-- , and $-2004 \mathrm{c}$ : Effect of surface waves on Charnock coefficient under tropical cyclones. Geophys. Res. Lett., 31, L20302, doi:10.1029/2004GL020988.

Powell, M. D., S. H. Houston, L. R. Amat, and N. MorisseauLeroy, 1998: The HRD real-time hurricane wind analysis system. J. Wind Eng. Indust. Aerodyn., 77-78, 53-64.

— P. J. Vickery, and T. A. Reinhold, 2003: Reduced drag coefficient for high wind speeds in tropical cyclones. Nature, 422, 279-283.

Smith, S. D., and Coauthors, 1992: Sea surface wind stress and drag coefficients: The HEXOS results. Bound.-Layer Meteor., 60, 109-142.

Tang, Y. M., R. Grimshaw, B. Sanderson, and G. Holland, 1996: A numerical study of storm surges and tide, with application to the north Queensland coast. J. Phys. Oceanogr., 26, 27002711.

Toba, Y., N. Iida, H. Kawamura, N. Ebuchi, and I. S. F. Jones, 1990: The wave dependence of sea surface wind stress. $J$. Phys. Oceanogr., 20, 705-721.

Tolman, H. L., 2002: Validation of WAVEWATCH III version 1.15 for a global domain. NOAA/NWS/NCEP/OMB Tech. Note 213, 33 pp.

Walker, N. D., R. R. Leben, and S. Balasubramanian, 2005: Hurricane-forced upwelling and chlorophyll a enhancement within cold-core cyclones in the Gulf of Mexico. Geophys. Res. Lett., 32, L18610, doi:10.1029/2005GL023716.

Wu, J., 1982: Wind-stress coefficients over sea surface from breeze to hurricane. J. Geophys. Res., 87, 9704-9706.

Zeng, X., M. Zhao, and R. E. Dickinson, 1998: Intercomparison of bulk aerodynamic algorithms for the computation of sea surface fluxes using TOGA COARE and TAO data. J. Climate, 11, 2628-2644. 